TITLE:

\title{
When remembering the past suppresses memory for future actions
}

$\operatorname{AUTHOR}(S)$ :

Utsumi, Kenta; Saito, Satoru

CITATION:

Utsumi, Kenta ...[et al]. When remembering the past suppresses

memory for future actions. Memory 2016, 24(4): 437-443

ISSUE DATE:

2016

URL:

http://hdl.handle.net/2433/251212

\section{RIGHT:}

This is an Accepted Manuscript of an article published by Taylor \& Francis in Memory on 2 March 2015, available online:

http://www.tandfonline.com/10.1080/09658211.2015.1015573.; This is not the published version. Please cite only the published version.; この論文は出版社版でありません。引用 の際には出版社版をご確認ご利用ください。 
1 Running Head: RIF IN PROSPECTIVE MEMORY

2

3

4

5

6

7

8

16

17 Utsumi, K., \& Saito, S. (2016). When remembering the past suppresses memory for future

18 actions. Memory, 24, 437-443.
When remembering the past suppresses memory for future actions

Kenta Utsumi

Satoru Saito

Graduate School of Education, Kyoto-University

Phone: +81757533066

k.utsumi1226@gmail.com

saito.satoru.2z@kyoto-u.ac.jp the Ministry of Education, Culture, Sports, Science, and Technology in Japan.

We appreciate Akari Narahara and Yuuki Suzuki (Faculty of Education, Kyoto

University) for data collection.

19 
RIF IN PROSPECTIVE MEMORY

1

2

3 Remembering planned actions at the correct time in the future is an integral component of

4 prospective cognition. Recent studies on future remembering have led to suggestions that

5 prospective cognition might be based on past experience. To test this hypothesis, we focused

6 on retrieval-induced forgetting, which usually indicates that remembering past events

7 suppresses memory for related but different past events. The current study assessed retrieval-

8 induced forgetting in two kinds of event-based prospective memory tasks using either focal

9 or nonfocal cues for ongoing tasks. Participants studied six members from each of eight

10 taxonomic categories and then practiced recalling three of the six members from four of the

11 eight categories using category-stem cues. This retrieval practice suppressed the detection of

12 non-practiced members of the practiced categories during the prospective memory task with

13 nonfocal cues (Experiment 1) but not with focal cues (Experiment 2). The results suggest that

14 recall of certain items inhibits the function of the others as prospective memory cues, but only

15 if the prospective memory task does not largely share its processing with the ongoing task.

16

17 Keywords: prospective memory, retrieval-induced forgetting, memory for future actions,

18 remembering past events 


\section{RIF IN PROSPECTIVE MEMORY}

People can plan for future events (Jäger \& Kliegel, 2008) and remember actions that must be completed for an event at the appropriate time (e.g., Ellis, 1996; McDaniel \& Einstein, 2000). This prospective cognition is essential for adaptive social life and survival. Over the past two decades, studies have increased our knowledge of prospective cognition (e.g., Schacter, Addis, \& Buckner, 2008). One of the most striking recent findings is that large swaths of cognitive and neural mechanisms are shared between remembering the past and imagining the future (although there are certainly differences between the two processes: see Schacter, Gaesser, \& Addis, 2012). Thus far, researchers have successfully identified the nature of similarities (e.g., Addis, Wong \& Schacter, 2008; Okuda, Fujii, Ohtake, Tsukiura, Tanji, Suzuki, Kawashima, Fukuda, Itoh, \& Yamadori, 2003) and differences (e.g., Addis \& Schacter, 2008; Storm \& Jobe, 2012) between remembering the past and prospective cognition. We add to this line of research by demonstrating how remembering the past affects prospective memory (PM), which is an integral part of, or which largely overlaps, prospective cognition such as imagining, planning, and remembering future events (e.g., Dobbs \& Reeves, 1996; Ellis, 1996).

Remembering certain past events suppresses memory for different past events that are related to the remembered target memories (e.g., Anderson, Bjork, \& Bjork, 1994); this is known as retrieval-induced forgetting (RIF). For example, if you successfully remembered certain members of a category (e.g., grape and apple for the FRUIT category) from a list of to-be-remembered items, then you might have difficulty remembering other study items within the same category (e.g., banana or orange). In this study, we examined whether remembering past events suppresses memory for future actions. Specifically, we tested RIF in PM. 


\section{RIF IN PROSPECTIVE MEMORY}

1 in which participants were required to make a predetermined action (e.g., press a key) when

2 detecting predetermined target words while performing an ongoing task (e.g., phoneme

3 judgment of presented words). For the current study, target words were predetermined members of a given category (e.g., FRUIT) and some of the category members were retrieved

5 (retrieval practice) before engaging in the PM task. Namely, we followed Anderson et al.

6 (1994) for the procedure of the initial study phase and the retrieval-practice phase, but we

7 employed an event-based PM task for the final test phase rather than using a cued recall (e.g.,

8 Anderson et al., 1994, Norman, Newman, \& Detre, 2007) or recognition task (e.g., Hicks \&

9 Starns, 2004).

We predicted that if remembering the past (i.e., retrospective memory, or RM, retrieval) and PM share common underlying mechanisms, then the retrieval practice should induce forgetting during the event-based PM task, and we could then argue that such episodic retrieval could affect processing of PM, which might operate with episodic representations for a successful future action. In fact, Clune-Ryberg et al. (2011) suggested that RM is a contributor to event-based PM by showing a significant correlation between PM cue detection rates and RM measures (see, Smith \& Bayen, 2004; Nowinski \& Dismukes, 2005 for similar conclusions). This indicates that PM functions could be affected by cognitive controls based on RM, or at least the PM functions could operate with some PM mechanisms. task becomes a focal cue when there is substantial overlap between processing for the ongoing task and that for the target event (e.g., both require a certain type of semantic processing). On the other hand, a target event becomes a nonfocal cue when there is little or no overlap between processing for the ongoing task and that for the target event (e.g., 


\section{RIF IN PROSPECTIVE MEMORY}

1

semantic processing for target events and phonological processing for the ongoing task).

McDaniel, Einstein, Guynn, and Breneiser (2004) indicated that, when PM cues were focal to an ongoing task, PM remembering would not need strategic and conscious monitoring, but require spontaneous retrieval, which could be facilitated/driven by stimuli in the environment. For example, Scullin, McDaniel, Shelton, and Lee (2010) reported that the costs to ongoing activity (task-interference) were minimal, while participants retained high performance on the focal PM task. Such spontaneous/automatic retrieval of the PM action from a focal cue might minimize any effects of RIF. Einstein et al. (2005) suggested that we rely on strategic monitoring with nonfocal targets. This strategic monitoring was considered to be a non-automatic capacity-demanding process. In accord with this, Marsh, Hancook, and Hicks (2002) demonstrated that, when an ongoing task required more resources, participants performed more poorly on the PM task when this task was nonfocal to the ongoing task. In such a situation with nonfocal cues, we might need to employ conscious access to episodic representations of the target word for PM retrieval, which consequently might be affected by retrieval practice. Previous studies raised the possibility that cognitive processes for PM remembering differ depending on whether PM cues were focal or nonfocal to the ongoing task. We aimed to examine the influence of retrieval practice on the two different types of PM remembering.

We employed an event-based PM task that was driven by semantic categories in two experiments. The category-based PM target detection we used is not a typical explicit memory task, but this detection task is similar to a category-verification task. Perfect, Moulin, Conway \& Perry. (2002) reported RIF even when tasks were implicit or indirect, if the tasks involved processing of categorical information, such as category-generation or category-verification. As the current study is the first to examine RIF in a prospective 


\section{RIF IN PROSPECTIVE MEMORY}

1

2

memory task, we used a task that was sensitive to the retrieval practice manipulation. Also we informed participants about the relationship between study and test phases as test awareness affects RIF in indirect test tasks (Camp Pecher, and Schmidt, 2005). The task used in Experiment 1 was a phoneme detection task that would not require access to semantics, while that in Experiment 2 was a heaviness judgment task that could potentially require access to semantic memory. Thus we defined the former as a nonfocal task and the latter as a focal task. Note that this nonfocal-focal contrast is based on the relative degree of involvement of semantics in the tasks, and thus we do not deny that the heaviness judgment task used in Experiment 2 held nonfocal components to some extent, i.e., processing that would not overlap with the PM detection task. Nonetheless, we believe that this relative difference is sufficient to provide a meaningful focal versus nonfocal distinction.

\section{EXPERIMENT 1}

\section{Method}

\section{Participants}

Forty-eight undergraduate students (25 men and 23 women) from Kyoto University participated in this experiment and received a book coupon (500 JPY) for their participation. All participants were native Japanese speakers aged between 19 and 25 years.

\section{Procedure}

The experiment consisted of three phases: a study phase, a retrieval-practice phase, and a test phase. During the study phase, participants were required to memorize 48 categoryexemplar pairs (six members from eight categories). Pairs (e.g., ANIMAL-rabbit, in Japanese) were presented one at a time for $5 \mathrm{~s}$ on a computer monitor. The categories were Animal, Fruit, Vehicle, Sports, Musical instrument, Drink, Stationery, and Country. During 


\section{RIF IN PROSPECTIVE MEMORY}

1

2

the retrieval-practice phase, all participants received a booklet in which each page contained a category name with the first two letters of a studied exemplar. Participants were required to complete the exemplar word by filling in the missing part of the word. This retrieval practice was carried out for three category members for each of four categories among the eight studied categories. Each of the 12 pairs appeared three times in this booklet. These 12 items were named $\mathrm{Rp}+$ items. The other 12 items that were not used during the retrieval-practice phase but were derived from the retrieval-practice categories were called Rp- items.

Therefore, each of four practiced categories contained three $\mathrm{Rp}+$ items and three $\mathrm{Rp}$ - items. Items from non-practiced categories were called Nrp items. The selection of four practiced categories and three members from each of the four categories was counterbalanced across participants.

$$
\text { During the final test phase, participants performed an event-based PM task. }
$$

Participants viewed a list of 260 words presented one at a time and performed a phoneme detection task (detecting the phoneme $/ \mathrm{k} /$ in each word) continuously as an ongoing task. While performing this task, the event-based PM task required participants to press the space bar on a keyboard when they encountered a target word, which was a member of one of three pre-determined categories that were used during the study phase. Thus, the three target categories were selected from the eight studied categories: two from the four practiced categories (one category for two $\mathrm{Rp}+$ targets and one for two $\mathrm{Rp}$ - targets) and one from nonpracticed categories (for two Nrp targets). Therefore, this PM task included two Rp+ cues, two Rp- cues, and two Nrp cues. These six PM cues that each participant had to detect during this test were derived from the words studied in the initial study phase (and this point was explicitly instructed to participants). The selection of two practiced categories and one nonpracticed category was also counterbalanced across participants. 


\section{RIF IN PROSPECTIVE MEMORY}

The target word appeared every 40 trials (six times in total: twice for each of the three target types, i.e., Rp+, Rp- and Nrp) with the first target appearing at the 48th position (i.e., cues occurred on trials numbered 48, 89, 130, 171, 212, and 253). The order of target type was counterbalanced.

\section{Results}

Participants correctly recalled $97.92 \%$ of $\mathrm{Rp}+$ items during the retrieval-practice phase.

Performance on the phoneme detection task (the ongoing task) during the test phase was high; the overall correct answer rate across all blocks was $93.47 \%$. The average response time was $1169 \mathrm{~ms}(\mathrm{SD}=517)$.

Figure 1 shows the target detection rates for the PM task. We conducted a withinsubjects one-way analysis of variance (ANOVA) with three levels specifying item classes (i.e., $\mathrm{Rp}+$, Rp-, and Nrp). A significant main effect of target type $(F(2,94)=19.55, p<.01$, $\left.M S E=0.09, \quad \eta^{2}=.17\right)$ was revealed. Ryan's post-hoc analysis revealed that the target detection rate for Rp- targets was significantly lower than that for Nrp targets (Hedge's $g=$ 0.53), and there was a significant difference in the detection rates between $\mathrm{Rp}+$ and $\mathrm{Nrp}$ targets (Hedge's $g=0.61)$.

\section{Discussion}

This experiment demonstrated RIF in an event-based PM task. Consequently, remembering past events (retrieval practice) suppressed memory for future actions when processing in the ongoing task did not directly promote the detection of PM cues (with nonfocal cues) that drive the retrieval of actions. Therefore, we suggest that remembering the past has an inhibitory effect on PM remembering. 
RIF IN PROSPECTIVE MEMORY

In the next experiment, we examined RIF in a PM task with focal target cues, the processing of which overlaps with processing of an ongoing task; thus, the cues potentially promote spontaneous retrieval of the target words.

\section{EXPERIMENT 2}

\section{Methods}

\section{Participants}

Forty-eight undergraduate students (24 men and 24 women) from Kyoto University participated in this experiment and received a book coupon (500 JPY) for their participation. All participants were native Japanese speakers aged between 18 and 24 years and did not participate in Experiment 1.

\section{Procedure}

The main purpose of this study was to examine whether RIF could be observed in an event-based PM task. Hence, the use of category-exemplar pairs were essential for this study and we could not alter the event-based PM task from the category detection task that we employed in Experiment 1. For this reason, we changed the ongoing task from a phoneme detection task so that the event-based PM task used in Experiment 1 became focal to the ongoing task.

The procedure was the same as described in Experiment 1, except that we used a heaviness judgment task as the ongoing task. In this task, participants saw a list of 260 words presented one at a time and had to determine whether the object that each word represented was heavier than 500 grams or not. This heaviness task inevitably requires participants to access semantic information for the word, which should also be required for the category member judgment in the PM task. In consequence, the ongoing task and PM task in this 


\section{RIF IN PROSPECTIVE MEMORY}

experiment shared a substantial amount of processing. Among the eight categories used in Experiment 1, SPORT, DRINK, and COUNTRY categories were not suitable for cues in the PM task because we could not measure the weight of members in those categories, although participants did not need to make a weight judgment on the PM targets. To substitute, we adopted new three categories-FISH, FURNITURE, and VEGETABLE-whose members could be weighed. Other than the change of studied categories, the procedures for the eventbased PM task were the same as in Experiment 1.

phase. Performance on the weight-judgment task (the ongoing task) during the test phase was high; the overall mean correct answer rate across all blocks was $82.84 \%$. The average response time was $1408 \mathrm{~ms}(\mathrm{SD}=956)$

Figure 2 shows the correct target detection rates for the PM task. We conducted a within-subjects one-way ANOVA with three levels specifying the classes of items (i.e., Rp+, Rp-, and Nrp) and revealed a significant main effect of target type $(F(2,94)=7.61, p<.01$, $\left.M S E=0.08, \quad \eta^{2}=.07\right)$. Ryan's post hoc analysis revealed no significant difference between the target detection rate for Rp- and Nrp targets (Hedge's $g=0.14$ ) but a significant difference in the detection rates between Rp+ and Nrp targets (Hedge's $g=0.61)$.

\section{Discussion}

The experiment with the focal PM targets did not show RIF. When planned actions could be remembered relatively spontaneously, memory for future actions might not be susceptible to the inhibitory control based on remembering the past. As an enhanced detection 


\section{RIF IN PROSPECTIVE MEMORY}

1 for $\mathrm{Rp}+$ cues relative to Nrp cues was observed in this experiment, we can say that the

retrieval-practice manipulation was successful.

There is one caveat regarding whether spontaneous PM retrieval occurred in

Experiment 2, using the heaviness judgment task as the ongoing task. As we did not include a no-PM task control condition for our ongoing task, it is difficult for us to confirm that the assumed spontaneous PM retrieval did not affect the ongoing task performance. However, unlike Experiment 1, RIF in PM remembering was not observed in Experiment 2. This indicates at least that the two ongoing tasks (one in Experiment 1 and another in Experiment 2) required different cognitive processes.

\section{GENERAL DISCUSSION}

Many psychological studies have identified the nature of similarities (e.g., Addis et al., 2008; Okuda et al., 2003) and differences (e.g., Addis \& Schacter, 2008; Storm \& Jobe, 2012) between remembering the past and memory for future actions. Continuing these lines of inquiry, the current study demonstrated a direct influence of past experience on PM by showing RIF in event-based PM task with nonfocal targets. To our knowledge, this is the first demonstration of RIF in a PM task.

However, this cognitive control did not have any effect on PM remembering when the target cues for those actions were processed with some overlap with the ongoing task (i.e., focal cues). Einstein \& McDaniel (2005) argued that the occurrence of PM cues would reflexively trigger PM retrieval when PM cues were focal to the ongoing task. This meant that PM remembering would depend on PM cues rather than the participant's cognitive processing when focal cues were used. Consequently the reason why we did not see RIF in Experiment 2 could be that the processing for the heaviness judgment task might activate 


\section{RIF IN PROSPECTIVE MEMORY}

1

2

representations of $\mathrm{Rp}$ - items and release those from the inhibitory control derived from semantic retrieval (Anderson, 2003). Because of this release, Rp- cues would return their function to trigger spontaneous PM retrieval.

Another possible interpretation for the results of Experiment 2 was that because spontaneous PM retrieval with focal cues did not entail episodic remembering for participants, we did not see RIF in the focal PM task. This is consistent with the contextspecific view of RIF (e.g., Verde \& Perfect; 2011), which suggests that we only observe RIF when the original context in which inhibition took place is reinstated. It is possible to argue that the original contexts where inhibitory controls with episodic retrieval occurred (i.e. retrieval practice phase) were not recreated in the focal PM task of Experiment 2.

Regarding possible mechanisms of RIF, two explanations have been proposed thus far. First, according to the inhibitory account (e.g., Anderson, 2003), providing a category and a word stem during retrieval practice triggers a search that activates all items associated with that category. To overcome this retrieval competition, inhibitory control for related but unwanted items occurs during retrieval practice, reducing accessibility to Rp- items. RIF then occurs in the final memory test phase (Grundgeiger, 2014). Second, according to the interference-based theory (e.g., Camp, Pecher, Schmidt \& Zeelenberg, 2009), the cause of RIF is a relative weakening of the cue-target associations of unpracticed competitors. Therefore, this theory hypothesizes that RIF is seen because practiced $\mathrm{Rp}+$ items interfere with $\mathrm{Rp}$ - items during the final memory test. The main difference between these two theories is whether they assume inhibitory control during the retrieval-practice phase. As the present study was not designed to distinguish the two theories, it is difficult for us to provide a decisive suggestion as to which is more compelling. However, the data from the current experiments suggest that RIF could occur on memory for future actions, regardless of the 


\section{RIF IN PROSPECTIVE MEMORY}

1 precise mechanism of the effect (i.e., inhibition or interference).

2

In summary, retrieval practice for some exemplars from potential target categories

3 inhibited the function of the others as PM cues to drive PM remembering only when the PM

4 task did not largely share its processing with the ongoing task. Consequently, we can regard

$5 \quad \mathrm{PM}$ as a dynamic function, which is only subject to cognitive control driven by remembering

6 information in situations where automatic PM remembering is not supported. 
RIF IN PROSPECTIVE MEMORY

\section{References}

Addis, D. R., \& Schacter, D. L. (2008). Constructive episodic simulation: temporal distance and detail or past and future events modulate hippocampal engagement. Hippocampus, 18, 227-237.

Addis, D. R., Wong, A. T. \& Schacter, D. L. (2008). Age-related changes in the episodic simulation of future events. Psychological Science, 19, 33-41.

Anderson, M. C. (2003). Rethinking interference theory: Executive control and the mechanisms of forgetting. Journal of Memory and Language, 49, 415-445.

Anderson, M. C., Bjork, R. A., \& Bjork, E. L. (1994). Remembering can cause forgetting: Retrieval dynamics in long-term memory. Journal of Experimental Psychology: Learning, Memory, and Cognition, 20, 1063-1087.

Clune-Ryberg, M., Blanco-Campal, A., Carton, S., Pender, N., O’Brien, D., Phillips, J., . . . Burke, T. (2011). The contribution of retrospective memory, attention and executive func- tions to the prospective and retrospective components of prospective memory following TBI. Brain Injury, 25(9), 819-831.

Cohen, A. L, Jaudas, A., \& Gollwitzer, P. M. (2008). Number of cues influences the cost of remembering to remember. Memory \& Cognition, 36 (1), 149-159.

Dobbs, A. R., \& Reeves, B. (1996). Prospective memory: More than memory. In M. Brandimonte. Einstein, G. O. \& McDaniel, M. A. (Eds.), Prospective memory: Theory and applications (pp. 199-225). Mahwah, N.J.: L. Erlbaum.

Einstein, G. O., \& McDaniel, M. A. (1990). Normal aging and prospective memory. Journal of Experimental Psychology: Learning, Memory, and Cognition, 16 (4), 717-726.

Einstein, G. O. \& McDaniel, M. A. (2005). Prospective memory multiple retrieval processes. Current Directions In Psychological Science. 14 (6), 286-290. 


\section{RIF IN PROSPECTIVE MEMORY}

1 Ellis, J. (1996). Prospective memory or the realization of delayed intentions: A conceptual framework for research. In M. Brandimonte, G. O. Einstein \& M. A. McDaniel (Eds.), Prospective memory: theory and applications (pp. 1-51). Mahwah, N.J.: L. Erlbaum.

Grundgeiger, T. (2014). Noncompetitive retrieval practice causes retrieval-induced forgetting in cued recall but not in recognition. Memory \& Cognition, 42, 400-408.

Jäger, T. \& Kligel, M. (2008). Time-based and Event-based prospective memory across adulthood: Underlying mechanism and differential cost on the ongoing task. The Journal of General Psychology, 134 (3), 327-342.

Hicks, J. L. \& Starns, J. J. (2004). Retrieval-induced forgetting occurs in tests of item recognition. Psychonomic Bullein \& Review, 11 (1), 125-130.

Marsh, R. L., Hancook, W. T., \& Hicks, J. L. (2002). The demands of an ongoing activity influence the success of event-based prospective memory. Psychonomic Bulletin \& Review, 9 (3), 604-610.

McDaniel, M. A., \& Einstein, G. O. (2000). Strategic and automatic processes in prospective memory retrieval: A multipleprocess framework. Applied Cognitive Psychology, 14, S127-S144.

McDaniel, M. A., Einstein, G. O., Guynn, M. J., \& Breneiser, J. (2004). Cue-focused and reflexive-associative processes in prospective memory retrieval. Journal of Experimental Psychology: Learning, Memory, and Cognition, 30 (3), 605-614.

Norman, K. A., Newman, E. L., \& Detre, G. J. (2007). A neural network model of retrieval-induced forgetting. Psychological Review, 114, 887-953.

Nowinski, J. L. \& Dismukes, R. K. (2005). Effects of ongoing task context and target typicality on prospective memory performance: the importance of associative cueing. MEMORY, 13 (6), 649-657. 


\section{RIF IN PROSPECTIVE MEMORY}

1 Okuda, J., Fujii, T., Ohtake, H., Tsukiura, T., Tanji, K., Suzuki, K., ...Yamadori, A. (2003). Thinking of the future and past: the roles of the frontal pole and the medial temporal lobes. Neuroimage, 19, 1369-1380.

Perfect, T. L., Moulin, C. J. A., Conway, M. A. \& Perry, E. (2002). Assessing the inhibitory account of retrieval-induced forgetting with implicit-memory tests. Journal of Experimental Psychology: Learning, Memory, and Cognition, 28 (6), 1111-1119.

Schacter, D. L., Addis, D. R., \& Buckner, R. L. (2008). Episodic simulation of future events: concepts, data, and applications. Annals of the New York Academy of Sciences, $1124,39-60$.

Schacter, D. L., Gaesser, B., \& Addis, D. R. (2012). Remembering the past and imaging the future in the elderly. Gerontology, 59 (2), 143-151.

Scullin, M, K., McDaniel, M. A., Shelton, J. T., \& Lee. J. H. (2010). Focal/Nonfocal cue effects in prospective memory: Monitoring difficulty or different retrieval processes? Journal of Experimental Psychology: Learning, Memory, and Cognition, 36 (3), 736-749.

Smith, R. E \& Bayen, U. J.(2004). A multinomial model of event-based prospective memory. . Journal of Experimental Psychology: Learning, Memory and Cognition, 30 (4), $756-777$.

Storm, B. C., \& Jobe, T. A. (2012). Remembering the past and imaging the future: examining the consequences of mental time travel on memory. Memory, 20, 224-235.

Verde, M. F. \& Perfect, T. J. (2011). Retrieval-induced forgetting in recognition is absent under time pressure. Psychonomic Bulletin \& Review, 18, 1166-1171. 
RIF IN PROSPECTIVE MEMORY

1

2

3 Figure 1. Proportion of correct target detection and standard errors for three target types in a

4 nonfocal event-based PM task in Experiment 1.

5

$6 \quad$ Figure 2. Proportion of correct target detection and standard errors for three target types in a

7 focal event-based PM task in Experiment 2.

8

9
Figure Captions 
RIF IN PROSPECTIVE MEMORY

1

2

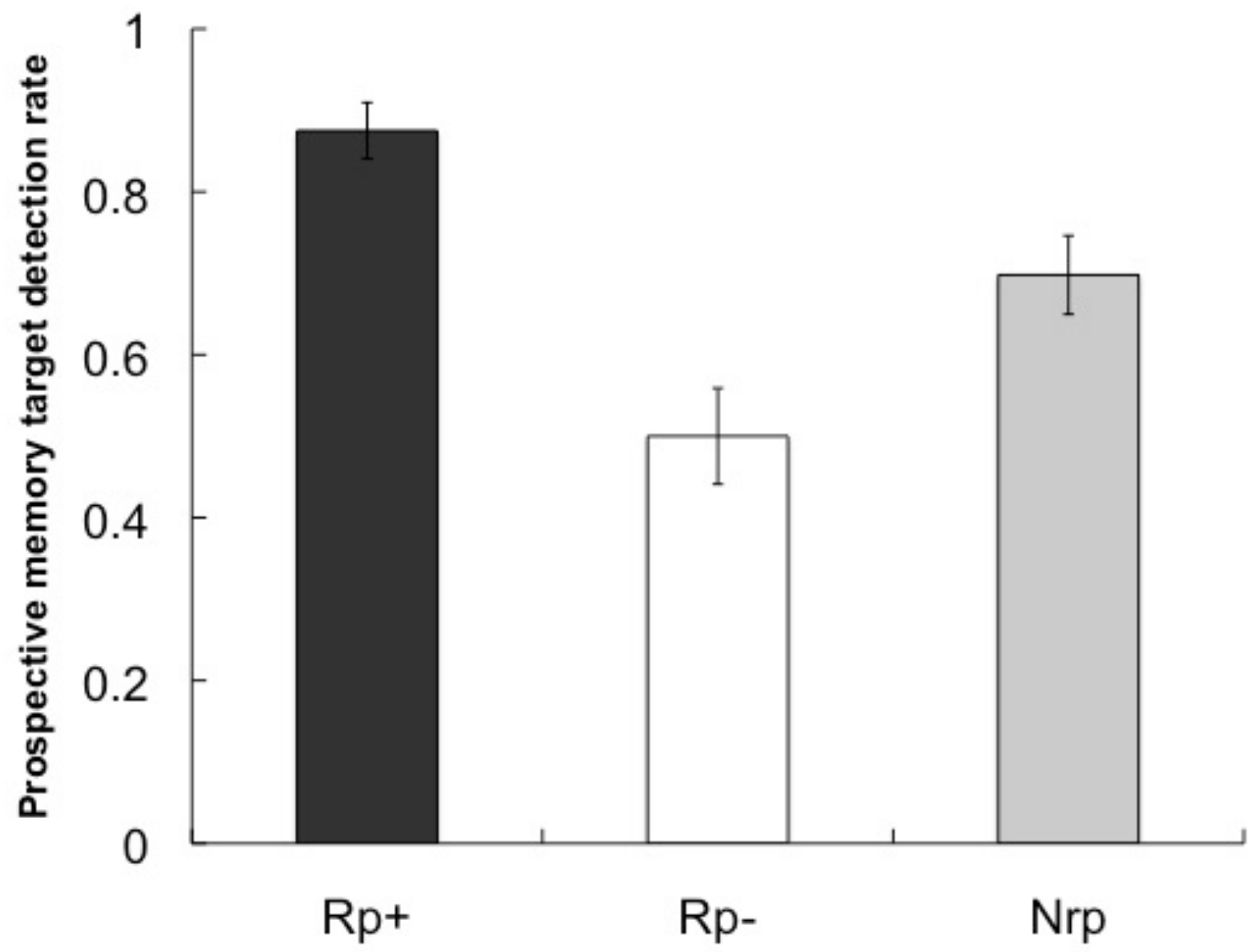

3

4

5

6

7

8

9

10

11

12

13

14

15

16

17

18

19

20

21

22 
RIF IN PROSPECTIVE MEMORY

1

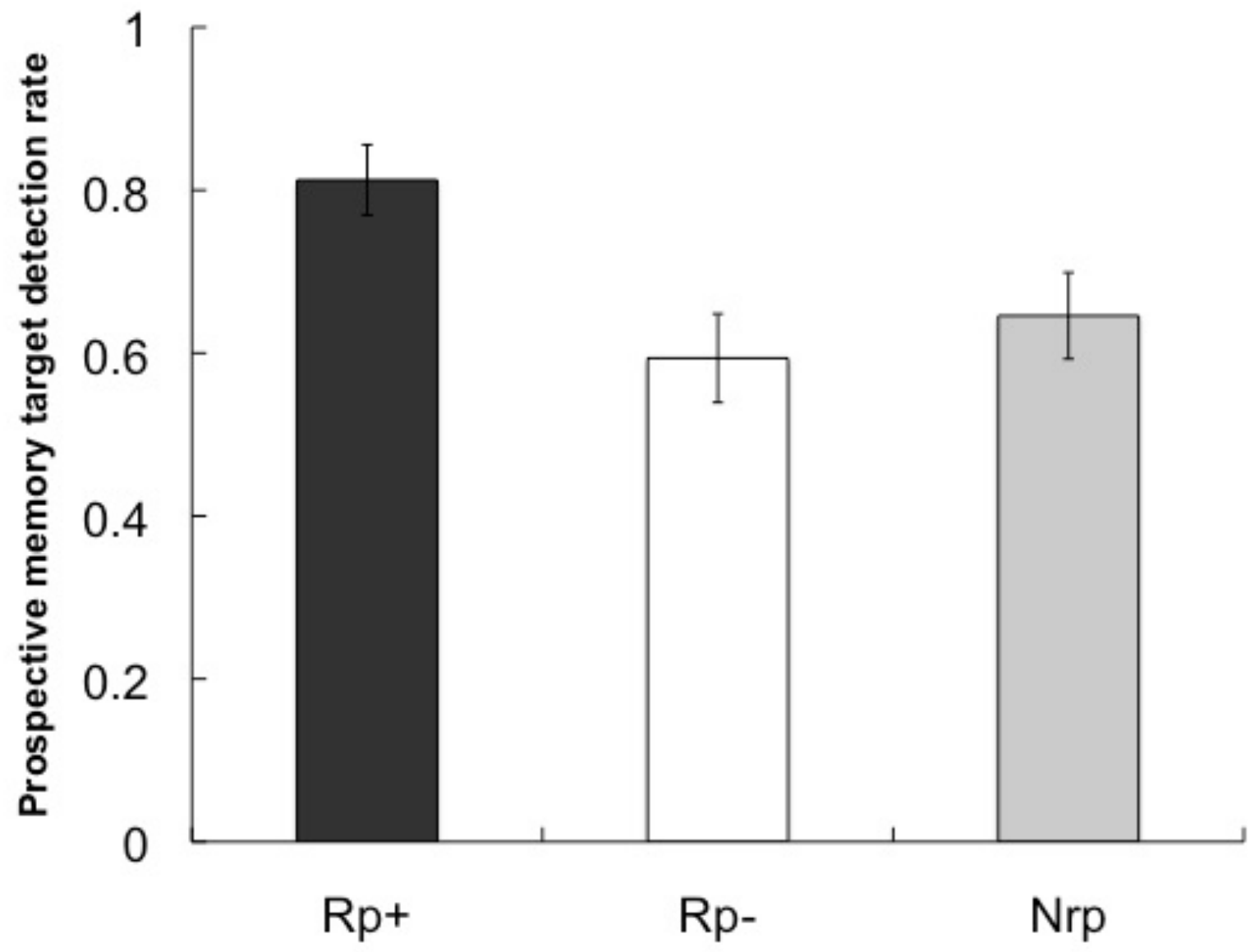

2
3 